\title{
Assembly of photosynthetic apparatus in Rhodobacter sphaeroides as revealed by functional assessments at different growth phases and in synchronized and greening cells
}

\author{
M. Kis • E. Asztalos • G. Sipka •P. Maróti \\ The publisher's version: Photosynth Res (2014) 122:261-273; DOI 10.1007/s11120-014-0026-4
}

\begin{abstract}
The development of photosynthetic membranes of intact cells of Rhodobacter sphaeroides was tracked by lightinduced absorption spectroscopy and induction and relaxation of the bacteriochlorophyll fluorescence. Changes in membrane structure were induced by three methods: synchronization of cell growth, adjustment of different growth phases and transfer from aerobic to anaerobic conditions (greening) of the bacteria. While the production of the bacteriochlorophyll and carotenoid pigments and the activation of light harvesting and reaction center complexes showed cell-cycle independent and continuous increase with characteristic lag phases, the accumulation of phospholipids and membrane potential (electrochromism) exhibited stepwise increase controlled by cell division. Cells in the stationary phase of growth demonstrated closer packing and tighter energetic coupling of the photosynthetic units (PSU) than in their early logarithmic stage. The greening resulted in rapid (within 0-4 h) induction of BChl synthesis accompanied with a dominating role for the peripheral light harvesting system (up to LH2/LH1 $\sim 2.5)$, significantly increased rate $(\sim 7104 \mathrm{~s}-1)$ and yield $\left(\mathrm{F}_{\mathrm{v}} / \mathrm{F} \max \sim 0.7\right)$ of photochemistry and modest $(\sim 2.5$-fold $)$ decrease of the rate of electron transfer $(\sim 1.5104 \mathrm{~s}-1)$. The results are discussed in frame of a model of sequential assembly of the PSU with emphasis on crowding the LH2 complexes resulting in an increase of the connectivity and yield of light capture on the one hand and increase of hindrance to diffusion of mobile redox agents on the other hand.
\end{abstract}

\section{Introduction}

In free energy converting biomembranes of living organisms, a transmembrane gradient of electrons, protons and/ or other species is created that covers the costs of energy consuming physiological processes including communication, growth or division (Wraight 2006). The transmembrane potential in photosynthetic bacteria is induced by light absorption of the light harvesting (antenna) complexes (LH) that funnel the electronic excitation energy to the reaction center $(\mathrm{RC})$ protein. In the $\mathrm{RC}$, charge separation occurs between the excited primary electron donor $\mathrm{P}$, a bacteriochlorophyll dimer, and the secondary electron acceptor Qв which is a quinone molecule. The stabilization of these separated charges occurs through subsequent electron transfers from the secondary donor (cytochrome $\mathrm{c}_{2}$ ) in the periplasmic space to the pool of quinones $(\mathrm{Q})$ in the hydrophobic domain of the membrane. They act as electron transfer shuttles between two membrane bound proteins, the RC and the cytochrome bci complexes. The cyclic electron transfer through the RC is accompanied with net uptake of protons from the cytoplasm and transfer to the periplasm. The light-induced protonmotive force completed by the cytochrome bci complex drives ATP synthesis. The key players and the fundamental processes in photosynthetic bacteria are arranged on a wide range of hierarchy in space (from cells to atoms of key biomolecules) and time (from ps to s), respectively, as shown artistically in Fig. 1 constructed on basis of recent atomiclevel model of the purple bacterium Rhodobacter sphaeroides (Cartron et al. 2014). The spatial arrangement of the molecular complexes in the membrane is crucial to convert the light energy to electrochemical potential and to achieve efficient and fast (cyclic) electron transfer resulting in transmembrane potential (Tucker et al. 2010). Photoheterotrophically growing purple bacterium Rba. sphaeroides represents the most thoroughly investigated species that shows remarkable versatility and metabolic elegance. It is capable of growth by aerobic and anaerobic respiration, fermentation, and anoxygenic photosynthesis. Therefore, it provides an excellent model system for simultaneous study of both photosynthesis and membrane development and for addressing significant problems in many areas of interest in cell biology, physiology, and bioenergetics. The bacterium contains three distinct membrane systems: the intracytoplasmic membrane (ICM), cytoplasmic membrane (CM), and outer membrane with their own unique macromolecular composition and structure. The ICM houses the photosynthetic apparatus. The ICM originates from the invagination of the $\mathrm{CM}$ that occurs at low (around $3 \%$ ) oxygen concentration (Kiley and Kaplan 1988) and at curved regions of the CM (Tucker et al. 2010). The extensive system of ICM facilitates 
the more effective absorption and utilization of light energy. The pheophytin-quinone type RC is surrounded by the internal light harvesting antenna (LH1) and the PufX protein and a peripheral light harvesting complex (LH2) in the outer sphere of the core complex. The RC-LH1-PufX complex is a dimer (Qian et al. 2008) and participates in light-induced cyclic electron transfer (Asztalos and Maro 'ti 2009). The ICM in Rba. sphaeroides adapts to alterations in light intensity (Aagaard and Sistrom 1972) and oxygen tension (Woronowicz et al. 2013; Niederman 2013). The invagination of the CM and the synthesis and assembly of light harvesting and RC complexes are under the control of a global two-component oxygen sensing, signal transduction system and additional regulatory components (Takemoto and Lascelles 1973; Masuda and Bauer 2002; Fedotova and Zeilstra-Ryalls 2014). Despite the elucidation of the regulatory system and its impact on gene transcription in response to changes in oxygen availability (Gomelsky and Zeilstra-Ryalls 2013), very little is known about the multi-level regulation of the mechanisms governing formation and function of the photosynthetic apparatus (Young and Beatty 2003).

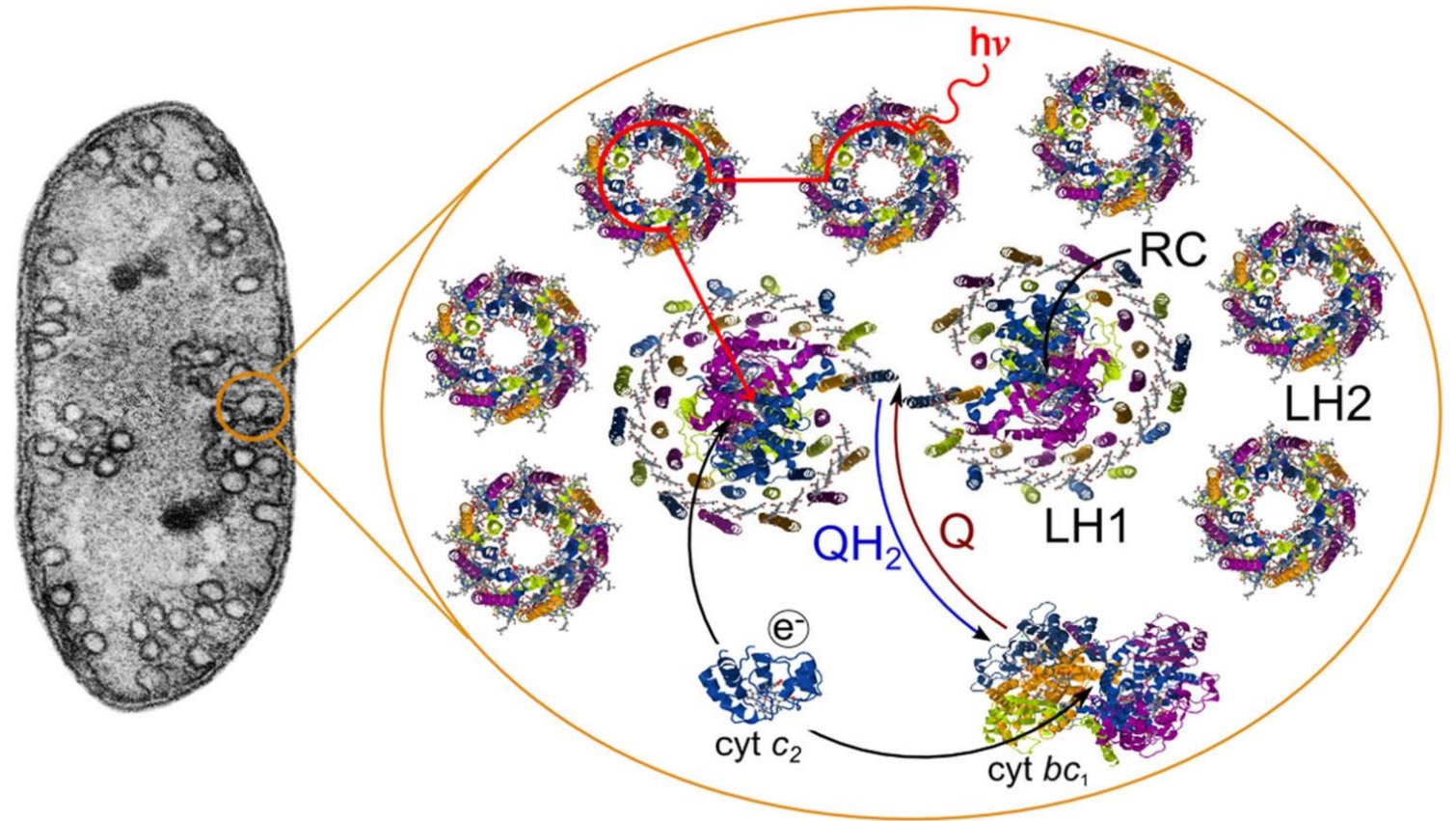

Fig. 1 Illustration of the hierarchy of organization of the photosynthetic apparatus of Rba. sphaeroides: intact cell (left) and model of the native architecture of the photosynthetic membrane with key players of light capture, migration of electronic excitation energy, charge separation and cyclic electron transfer: the light harvesting (peripheral (LH2) and core (LH1)) complexes, dimeric reaction center (RC) protein, cyt bc1 complex and mobile electron carriers cyt $\mathrm{c}_{2}$ and $\mathrm{Q}$ (right). Top view of the intracytoplasmic membrane with atomic resolution of the complexes (sources: RCSB Protein Data Bank and Cartron et al. 2014)

The organization of the complexes resulting in the physiological function of the apparatus has been characterized by high atomic resolution and at an unprecedented level of biochemistry and physical chemistry (Bahatyrova et al. 2004; Sener et al. 2007; Sener and Schulten 2009; Maro 'ti et al. 2013). There are, however, a number of open questions that are as yet unanswered. One of the major problems currently involves the location of the cytochrome bc1 complex and the ATP synthase and the stoichiometry of the partners. The functional and spectroscopic measurements indicate loose assembly between RCs and bcicomplexes connected by mobile redox species. The stoichiometry of 2 (dimeric) RC, 1 cyt bc1, and 1 cyt c2 is generally accepted in ICM of Rba. sphaeroides (Joliot et al. 1989; Vermeglio and Joliot 2014). Novel advances of highresolution atomic force microscopy (AFM) analysis, however, do not reveal cytochrome bc1 complexes in the membrane areas of the core complexes and the ATP synthase is also absent (Scheuring 2009; Sturgis and Niederman 2009). This would mean that neither the cytochrome bc1 complexes nor the ATP synthase are in the proximity of the core complexes. The lack of connectivity based on AFM studies may be attributed to real disconnection of the complexes. This has generated a renewed interest in possible long-range pathways for lateral diffusion of UQ redox species that functionally link the RC and the bc1 complexes (Comayras et al. 2005). In Rba. sphaeroides (in contrast to e.g., Rps. rubrum), the arrangement of $\mathrm{LH}$ and $\mathrm{RC}$ complexes is highly organized and the RC electron transfer turnover is fast (Kocsis et al. 2010). The packing density of the peripheral antenna in the ICM, however, imposes constraints that significantly 
slow the diffusion of UQ redox species between the RC and cytochrome bc1 complex in the membrane (Woronowicz et al. 2012) and decrease the rate of electron transfer at the onset of greening (Koblizek et al. 2005; Woronowicz et al. 2013; Niederman 2013). The possibility of artifacts of the AFM measurements, however, cannot be disregarded. (1) During membrane preparation, the long-range order of the complex assembly in the native membrane can be altered or even the complexes can be removed. (2) The membrane fragments lacking cytochrome bc1 or ATP synthase can show preferential adsorption to the AFM support. (3) The face of the cyt bc1 complex exposed to the cytoplasm shows very little surface topology for identification by AFM. Indeed, the very recent results based on AFM, electron microscopy, and mass spectrometry can be contrasted to those of earlier AFM findings and are consistent with cyt bc1 complexes positioned adjacent to RC-LH1-PufX complexes with weak, but non-stoichiometric interaction (Cartron et al. 2014). The demonstrated proximity of the cyt bc1 and RC- LH1PufX complexes has consequences on the effective confinements of extrinsic mobile redox agents quinones and cytochrome c2, that must cycle between these complexes. The redox species may visit several cyt bc1 complexes (Crofts et al. 1998) and a timescale of 1-2 ms can be assured for the cyclic electron transfer. In this report, we study the ICM remodeling processes in Rba. sphaeroides undergoing acclimation to different physiological conditions. Despite the global importance of light (solar) energy utilization, there are significant gaps in our understanding of the full complement of entities needed for the function and assembly of a photosynthetic membrane (Callister et al. 2006; Zeng et al. 2007). It is therefore of considerable interest to study how the highly organized structure becomes established during various physiological processes: (1) different growth phases of the bacteria (Asztalos et al. 2010a), (2) aerobic \$ anaerobic transitions that result in rapid induction of BChl synthesis ("'greening") (Koblizek et al. 2005) and disruption of the ICM and photosynthetic apparatus ('"bleaching"), respectively and (3) synchronization of the cell growth by either diluting late stationary phase cultures (Cutler and Evans 1966; Lueking et al. 1978), or application of dark-light cycles (Lueking et al. 1981). These changes induce remodeling of the ICM and can be used to investigate how do the essential constituents of the photosynthetic apparatus find their correct location and function, how the physical state and crowding of the membrane bilayer control the activity of the different components and what constraints are set against the diffusion of mobile redox species in different phases of membrane development.

\section{Materials and methods}

The photosynthetic purple bacterium Rba. sphaeroides 2.4.1 was grown in Sistro "m's medium (Sistro "m 1962) either in completely filled screw top vessels without oxygen (photoheterotrophic and anaerobic growth), or in half filled Erlenmeyer flasks sparged with a mixture of air and nitrogen provided by an air pump and a $\mathrm{N}_{2}$ container, respectively (photoheterotrophic and semiaerobic growth). The oxygen-to-nitrogen volumetric ratio of the gas mixture was adjusted by calibrated flow rate meters (rotameters). The oxygen tension balanced with $\mathrm{N}_{2}$ could be changed between $21 \%$ (air) and $0 \%$ (anaerobic condition). The medium was inoculated from a dense batch culture (1:100) and was illuminated by tungsten lamps that assured $13 \mathrm{~W} \mathrm{m-2}$ irradiance on the surface of the vessel as described earlier (Maro 'ti and Wraight 1988). For experiments of bleaching and induction (greening) of the ICM under aerobic and anaerobic conditions, respectively, the illuminated culture was sampled over a 24-h period for near-IR absorption spectra, pigment analyses and light induced absorption and fluorescence measurements. For studies of functional assessment at different growth phases, the cells were harvested at the lag phase $(* 1 \mathrm{~h})$ and early stationary phase $(* 26 \mathrm{~h})$ of growth. For synchronization of the cells, the cells in the logarithmic phase of growth were the inoculum (1:100) source for 3 times repeated dark-light periods $(3.5-3.5 \mathrm{~h})$. The response of phototrophically growing cultures to varying light and aerobic regimes and confirmation of the presence of division synchrony were directly determined by monitoring total cell number with calibrated Bu "rker counting chamber under light microscope.

\section{Steady-state absorption spectroscopy}

The steady-state near infrared absorption spectra of the cells during the growth were recorded at room temperature by a single beam spectrophotometer (Thermo Spectronic Helios). The baselines were corrected for light scattering, and the spectra were decomposed into 3 Gaussian components by least square Marquardt procedure (Marquardt 1963).

\section{Flash-induced absorption kinetics}

The kinetics of absorption changes of the whole cells induced by Xe flash or by laser diode (Roithner LaserTechnik LD808-2-TO3, wavelength $808 \mathrm{~nm}$ and power $2 \mathrm{~W}$ ) were detected by a home-constructed spectrophotometer (Maro 'ti and Wraight 1988). The oxidized bacteriochlorophyll dimer (P?) and the electrochromic shift (ECS) of 
the carotenoids in the photosynthetic membrane were detected at 798 and $525 \mathrm{~nm}$ (with reference to $510 \mathrm{~nm}$ ), respectively. The optical density of the samples was kept low [OD (808 nm) 10.1] and weak monochromatic detection light was used to keep the secondary effects negligible.

\section{Induction and relaxation of BChl fluorescence}

The induction and subsequent decay of the BChl a fluorescence of intact cells were measured by a home built fluorometer (Kocsis et al. 2010). The light source was a laser diode (808-nm wavelength and 2-W light power) that produced rectangular shape of illumination and matched the $800 \mathrm{~nm}$ absorption band of the LH2 peripheral antenna of the cells. The BChl a fluorescence (centered at $900 \mathrm{~nm}$ in mature cells) was detected in the direction perpendicular to the actinic light beam, with a near infrared sensitive, large area (diameter $10 \mathrm{~mm}$ ) and high gain Si-avalanche photodiode (APD; model 394-70-72-581; Advanced Photonix, Inc., USA) protected with an 850-nm high-pass filter (RG-850) from the scattered light of the laser. The usually very small deviation of the kinetics of the excitation from the rectangular shape was corrected by detection of the kinetics of extracted $\mathrm{BChl}$ a in organic solvent. The induction was measured during the actinic laser light and the dark-relaxation was tested by attenuated short (3 us) laser pulses in geometrical series.

\section{Extraction and assay of molecular components of the cells}

(a) BChl The BChl was extracted from the cells by acetone/ methanol $(7: 2 \mathrm{v} / \mathrm{v})$ mixture using the extinction coefficient of 75 mM-1 cm-1 at $770 \mathrm{~nm}$ (Clayton and Clayton 1981). (b) Phospholipids The phospholipids from the cell suspension were extracted by the method of Bligh and Dyer (1959) and the quantitative (colorimetric) determination of the inorganic phosphate was based on the Bartlett assay (Bartlett 1959). (c) RC The RC pigmentprotein complex was prepared and the concentration was determined according to (Maro 'ti and Wraight 1988). (d) Carotenoids The carotenoids were extracted from the cells by acetone/ methanol (7:2 v/v) mixture using the extinction coefficient of $128 \mathrm{mM}-1 \mathrm{~cm}-1$ at $484 \mathrm{~nm}$ (Clayton 1966).

\section{Results}

Effect of growth phase on membrane remodeling

The growth curve of the nonsulfur photosynthetic bacterium Rba. sphaeroides with well-defined lag, exponential and stationary phases is demonstrated in Fig. 2a. The error bars represent the standard deviations of the mean cell numbers including both the fluctuations in the light intensity and temperature during a particular cultivation and the variation in measurements due to different cultivations (the \# of replicates was 5). At different growth stages, the bacterium exhibits significant kinetic changes of the membrane energetization (Fig. 2b) and a remarkable gain in the variable component of the BChl fluorescence induction (Fig. 2c) and relaxation (Fig. 2d). As the cells progress through the logarithmic phase, large changes can be observed in the kinetics of flashinduced carotenoid band shift measured at $525 \mathrm{~nm}$ (vs. $510 \mathrm{~nm}$ ) (Fig. 2b). The time-dependence of absorbance change (electrochromism) evoked by flash excitation tracks the generation and decay of the membrane potential due to initial charge separation, transfer of electron, and protons in the membrane and finally discharge of the membrane capacitor, respectively (Feniouk and Junge 2009). $1 \mathrm{~h}$ after inoculating a fresh culture, the cells have a small abrupt increase of electrochromism followed by fast decay. The intact cells in stationary phase of growth (26 h) have additionally a second and slower increase followed by a much slower relaxation. The control of the cyt bc1 complex in energetization of the membrane is indicated by the effect of the bct inhibitor myxothiazol in mature cells: the relatively small sudden rise after the flash is attributed to the charge separation in the RC. The very slow discharge of the membrane is probably due to leakage or charge recombination. The better isolation of the membrane in mature cells can be rationalized by supposing tighter packing of the dielectrics of the membrane as cells age. 

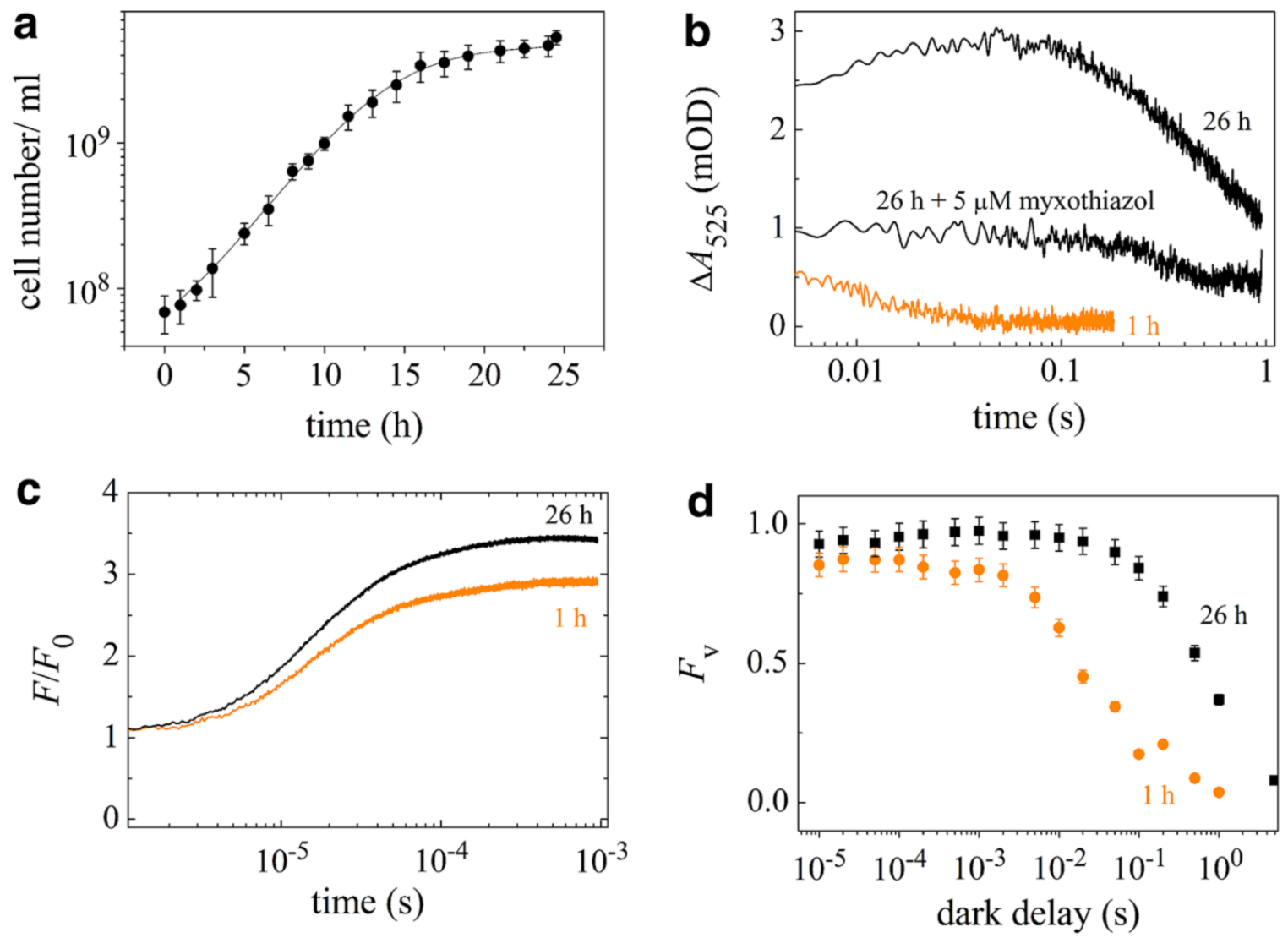

Fig. 2 Growth curve (a) and kinetics of flash-induced electrochromism (b), induction (c) and dark-relaxation (d) of BChl fluorescence of intact cells of Rba. sphaeroides in different physiological states: young (1 h, lag phase) cells and old (26 h, late logarithmic) cells. The fit (solid line) to the growth curve was achieved by Eq. (1). The flashinduced electrochromic shift was measured by absorption change at $525 \mathrm{~nm}(\mathrm{vs} .510 \mathrm{~nm})$ without and with $5 \mathrm{lM}$ myxothiazol known as efficient inhibitor of the cyt bc1 complex (b). The fluorescence (F) at $900 \mathrm{~nm}$ was excited by a rectangular shape of laser diode radiation (1 W

power at $808 \mathrm{~nm}$ ) of $1 \mathrm{~ms}$ duration and was related to that of the initial value $\left(\mathrm{F}_{0}\right)(\mathrm{c})$. The relative yield of variable fluorescence after the excitation, $F_{v}=\left(F-F_{\max }\right) /\left(F_{\max }-F_{0}\right)$ was monitored in the dark by attenuated weak $(100 \mathrm{~mW})$ and short

(3 ls) laser diode pulses arranged in geometrical series (d)

The BChl fluorescence measured after sudden dark $\rightarrow$ light transition (fluorescence induction) shows characteristic kinetics with $\mathrm{F}_{0}, \mathrm{~F}_{\mathrm{v}}$, and $\mathrm{F}_{\max }$ values of initial, variable and maximum levels of fluorescence, respectively (Fig. 2c). The fluorescence induction in the submillisecond time range has fairly simple kinetics in contrast to observation of multiple and unidentified phases in the 1-10 ms time scale (Bina et al. 2010) or to those of green plants (see for recent review by Stirbet and Govindjee 2012). The normalized variable fluorescence, $F_{v}=(F \max$ $\mathrm{F} 0 / \mathrm{F}_{0}$ is greater in $26 \mathrm{~h}$ cells than in $1 \mathrm{~h}$ cells. The increase in variable fluorescence may be attended by structural changes in the apparatus. In cells harvested in the stationary phase, the photosynthetic units (PSU) exhibit closer packing and tighter energetic coupling resulting in more efficient channeling of energy from the antenna to the $\mathrm{RC}$. The observed increase of photochemical utilization could be an adaptive response to decrease in light intensity usually prevalent in culture of stationary phase cells. The dark decay of the fluorescence after relatively long (1 ms) illumination shows marked difference between the cells at different growth phases (Fig. 2d). The mature (26 h) cells keep the high level of fluorescence longer than the lag phase $(1 \mathrm{~h})$ cells. As the relaxation is generally believed to depend on the re-opening time of the RC, the assay reflects the rate of cyclic electron transfer between the RC and the cyt bci complex (Koblizek et al. 2005). In stationary phase cells, the shuttle time of the electrons via mobile redox species cyt $\mathrm{c}_{2}{ }^{2+} / \mathrm{cyt}_{\mathrm{c} 2}{ }^{3+}$ and $\mathrm{QH} 2 / \mathrm{Q}$ between the complexes becomes longer probably due to rearrangement of the membrane resulting in slower diffusion and confinement of cytochrome $\mathrm{c} 2$ and quinones (Lavergne et al. 2009).

Synchronization of the culture 
This method facilitates the analysis of development of the ICM during steady-state growth of the cells. After several generations, the division of the cells can be synchronized by exposure of the culture to a sequence of darklight periods (Fig. 3). In steady-state synchronous culture, the number of cells increases stepwise as all of the cells are in the same stage of their development (Fig. 3a). Under the conditions of the experiment, the doubling time amounts about $3 \mathrm{~h}$. The advantage of the synchronization is the possibility to directly track the insertion of the photosynthetic apparatus into the old and newly formed ICM. In sharp contrast to the stepwise increase of the population, the production, insertion into the ICM and activation of the photosynthetic proteins (light harvesting, $\mathrm{RC}$ and cytochrome bc1 complexes) are cell-cycle independent processes, i.e., they do not follow a stepwise but rather a continuous process with well-defined lag phase at the beginning (Fig. 3b-d). Similar observations were reported earlier for the photopigments and RC by Wraight et al. (1978). For quantitative evaluation of the asynchronous anaerobic growth, the curves were fitted by the modified Gompertz equation (Zwietering et al. 1992; Asztalos et al. 2010b)

$$
\ln \frac{N}{N_{0}}=N_{\max } \cdot \exp \left\{-\exp \left[\frac{e \cdot \mu_{\max }}{N_{\max }}\left(t_{0}-t\right)+1\right]\right\}
$$

where $t$ is the time elapsed from the light exposure, to is the duration of the lag phase, No, N, and $\mathrm{N}_{\max }$ are the initial, actual, and maximum (saturating) values of the referred quantities (cell number, BChl fluorescence of the culture or concentration of pigments), respectively, and $1 \max$ is the maximum of the growth rate. Comparing the initial lag phases, similar values were found for the BChl $(2.35 \mathrm{~h})$, carotenoid $(2.87 \mathrm{~h})$ pigments and the rise of $\mathrm{BChl}$ fluorescence maximum $(3.1 \mathrm{~h}$ ), but significantly smaller value for the functional (light-induced oxidized) dimer in the RC protein $(1.52 \mathrm{~h})$. The rate of synthesis of the BChl pigment $\left(0.26 \mathrm{uM} \mathrm{h}^{-1}\right)$ proved to be somewhat lower than that of the carotenoids $\left(0.38 \mathrm{uM} \mathrm{h}^{-1}\right)$.
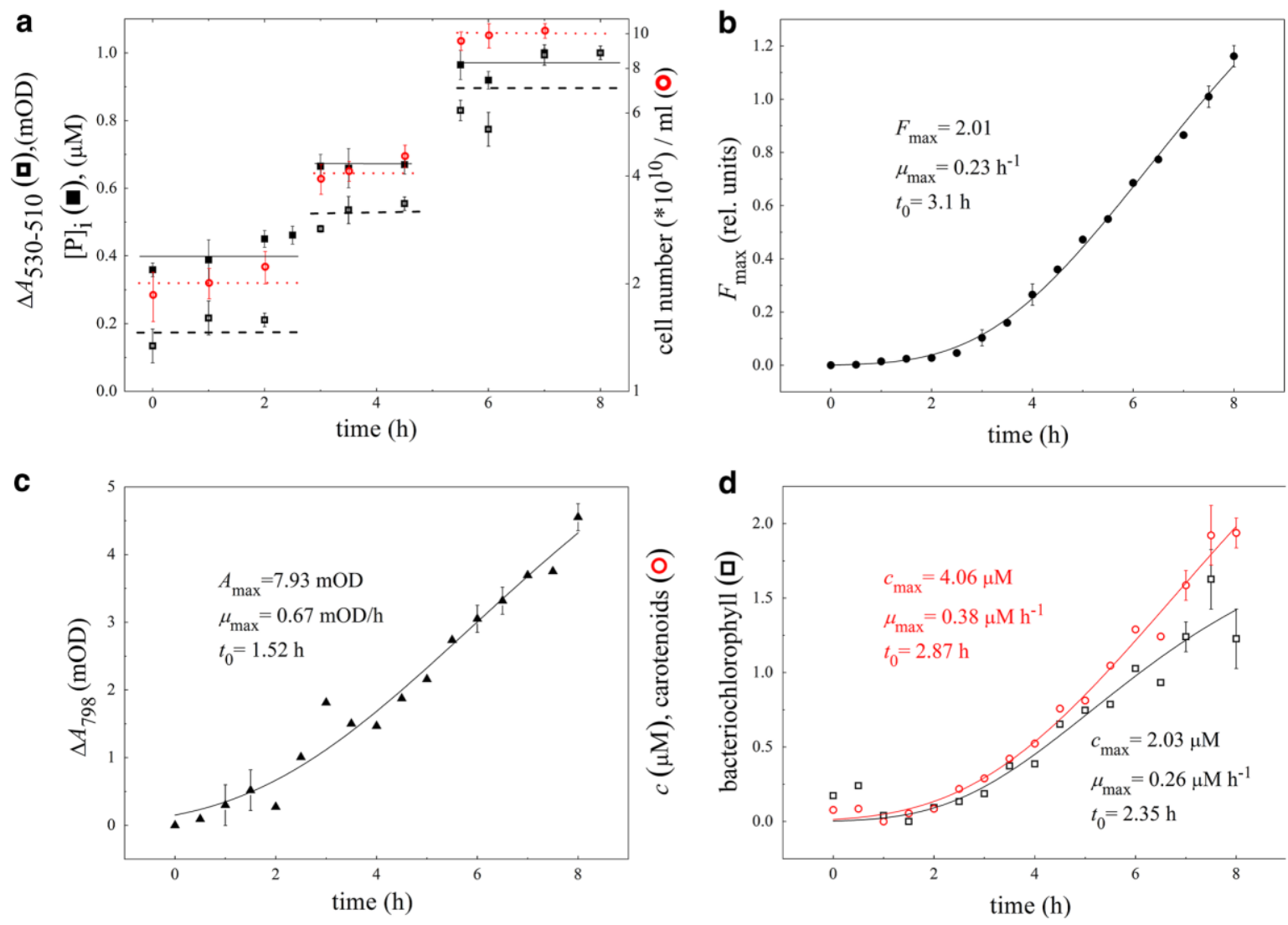

Fig. 3 Cell-cycle related (a) and independent (b-d) changes in synchronized culture of Rba. sphaeroides wild type 2.4.1. The discontinuous increase of the cell number, the total phosphate content of the cells and the amplitude of the electrochromic absorption change flash excitation demonstrate the stepwise assembly of ICM from phospholipids and its energetization upon division of the cell (a). The increase of the fluorescence maximum of BChl (b), the functional RC (measured by flashinduced absorption change of the cell at $798 \mathrm{~nm}$ arising from the oxidation of the dimeric BChl in the RC) (c) and the carotenoid and $\mathrm{BChl}$ content of the culture (d) are asynchronous during the cell cycle. The kinetics are approximated by the 
modified Gompertz equation (solid lines) with best fit parameters [saturation, maximum of the growth rate (umax) and duration of the lag phase (to)] indicated on the panels

In contrast to the continuous production of the pigments and the RC protein, the phospholipid synthesis (Knacker et al. 1985) and the electrochromic signal due to the cytochrome bc1 complex (Asztalos and Maro 'ti 2009) showed clear cell-cycle dependence (Fig. 3a.). The cellcycle dependent synthesis and accumulation of the phospholipids in the membrane are not unique to phototrophically grown cells. Reports were published about fluctuation in the rates of phospholipid synthesis and stepwise increase in total lipid content during the cell cycle of E. coli (Mozharov et al. 1985).

Anaerobic $\leftarrow \rightarrow$ aerobic transitions, ICM bleachinggreening regimen

The formation and disintegration of the ICM can be induced by modification of essential environmental factors. A convenient method is the control of oxygen content of the culture. As the formation of ICM and the synthesis of the photosynthetic components in Rba sphaeroides are under the control of a global two-component oxygen sensing, signal transduction system (Oh and Kaplan 2000; Bauer et al. 2009), they are repressed by high oxygen tension (bleaching) and induced at sufficiently low oxygen level (greening) (Takemoto and Lascelles 1973; Tucker et al. 2010; Niederman 2013). In our experiments, the preculture grown anaerobically in the light was adapted to high $(20 \%)$ oxygen tension for bleaching, and the greening was afterward induced by transferring the culture from aerobic to anaerobic conditions under illumination. The transitions induce major and characteristic changes of the growth rate of the bacterium, antenna composition, photochemical utilization of the light and coupling of the PSU (Fig. 4). The growth profile of the cells is shown in Fig. 4a. After switching from anaerobic to aerobic conditions, the cell number reaches within $10 \mathrm{~h}$ a saturation level that will be not significantly enhanced by subsequent transition to anaerobic conditions. The LH2 content (characterized by B850) does not change significantly during aerobic growth, but increases tremendously in the anaerobic environment (Fig. 4b). The steady-state near-IR absorption spectra demonstrate the large antenna changes during greening (Fig. 5a). The RC-LH1 core (875 nm) predominates over the first hours but after $2 \mathrm{~h}$, the peripheral LH2 complex (800-850 nm) starts to become dominating. The modification of the absorption spectra indicates changes of BChl stoichiometry and/or rearrangement of the antenna complexes. 


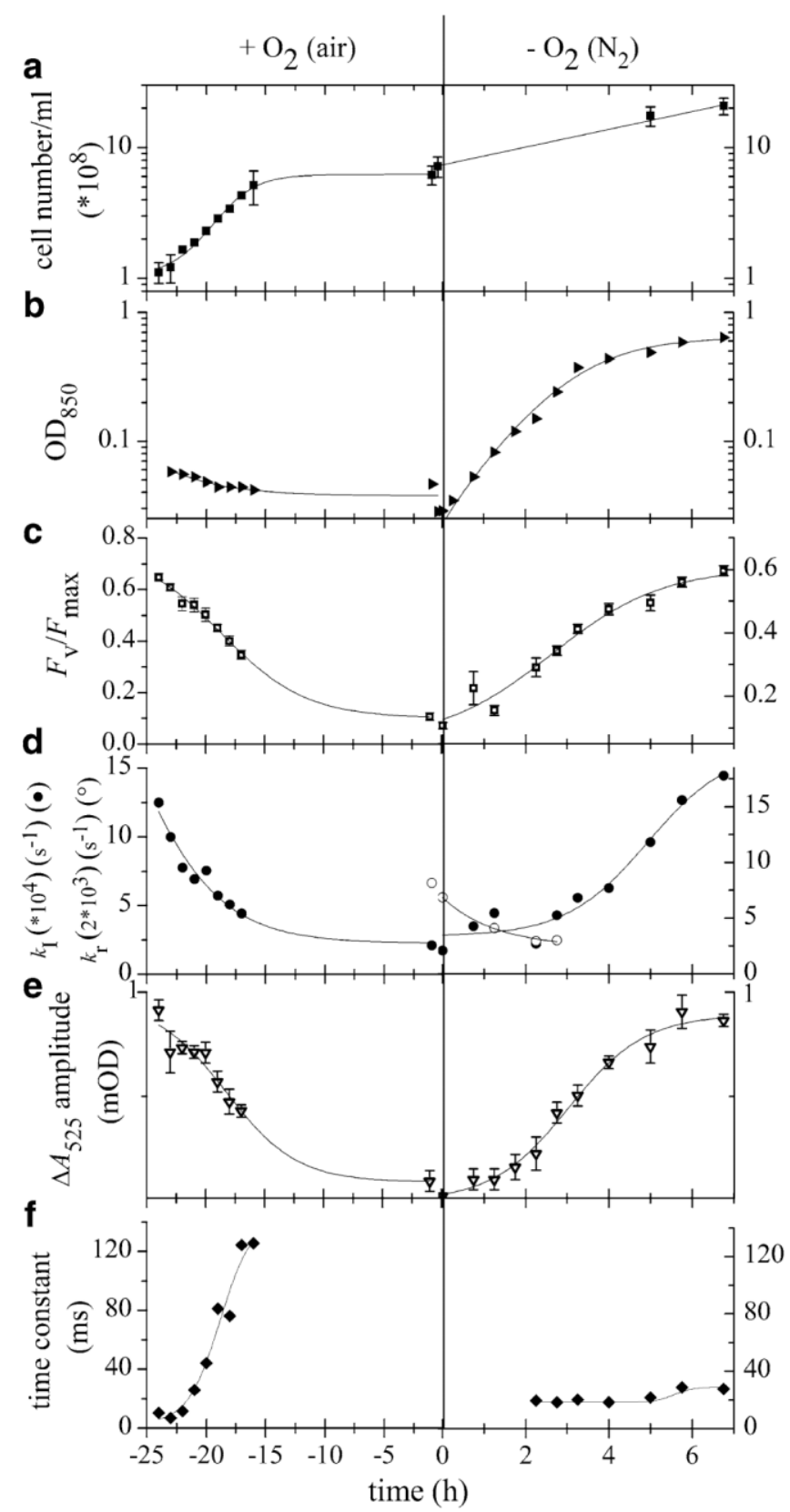

Fig. 4 Time-dependent structural and functional characteristics of photosynthetic membrane of Rba. sphaeroides grown aerobically $\left(+\mathrm{O}_{2}\right)$ and then transferred to anaerobic conditions $\left(-\mathrm{O}_{2}\right)$ (note the extended time scale). The increase of the cell number of the inoculated bacterium (a) includes depressed LH2 content under aerobic condition and exponential initial increase in nitrogen atmosphere $(b)$ and similar changes of the variable fluorescence $\left(F_{v}\right)$ to maximum fluorescence $\left(F_{\max }\right)(c)$ and the rate constants of photochemistry $(\mathrm{kI})$ and relaxation $(\mathrm{kr})$ of the variable fluorescence $(\mathrm{d})$. e, f The amplitude of the initial rise and decay constant of the flash-induced electrochromic change, respectively

The ratio of $\mathrm{BChl}$ variable fluorescence to maximum fluorescence exhibits marked changes (Fig. 4c): a slow drop from 0.70 to 0.10 within 1 day in aerobic environment that reverses within a couple of hours under an anaerobic atmosphere. The change is accompanied by a constant level of maximal fluorescence under aerobic conditions followed by a similarly fast rise as in $\mathrm{F}_{\mathrm{v}}$ (not shown). Figure $4 \mathrm{~d}$ indicates the changes of the rate constants of the rise of the fluorescence induction (kI) and the fluorescence relaxation $(\mathrm{kr})$. The kinetics of the rise of the fluorescence induction can be fairly well approximated by a monoexponential function, and the rate constant is proportional to the light intensity indicating the photochemical nature of the process. The decay of the $\mathrm{BChl}$ fluorescence in the dark is fast throughout the ICM formation and shows extended (complex) kinetics that can be decomposed formally by multiexponential functions only (Fig. 5b). The rate constant of relaxation introduced in 
Fig. $4 \mathrm{~d}$ is approximated by the average of the rate constants of the components weighted by their amplitudes. In case of proper theory, the derived rate constants $\mathrm{kI}$ and $\mathrm{kr}$ can be related to the size and connectivity of the PSU and to the rate of electron transfer, respectively (Koblizek et al. 2005; Rivoyre et al. 2010; Maro 'ti and Asztalos 2012). The amplitude (Fig. 4e) and decay times (Fig. 4f) of the flash-induced electrochromic response demonstrate also opposite changes during bleaching and greening. The progressive loss of photoactive RCs in aerobic environment is accompanied with improving storage capacity of the membrane. The energized new ICM under anaerobic conditions is discharged significantly faster than the old ICM in aerobic atmosphere.
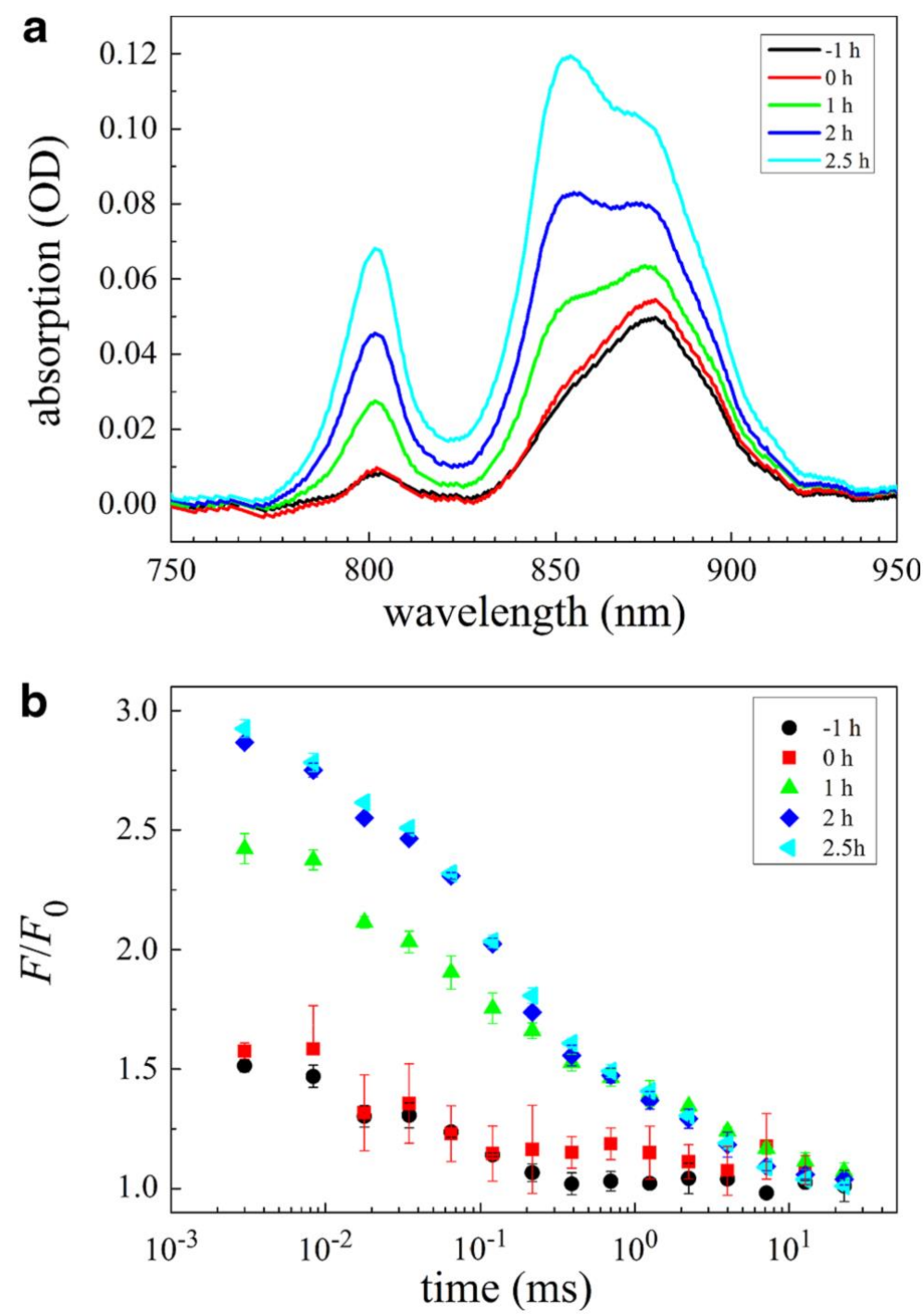

Fig. 5 Steady-state absorption spectra (a) and relaxation of BChl fluorescence (b) of intact cells undergoing induction of ICM upon transfer from aerobic to semiaerobic conditions at $\mathrm{t}=0$. The $\mathrm{LH} 1$ core and $\mathrm{LH} 2$ peripheral complexes correspond to spectral bands centered at $875 \mathrm{~nm}$ and $800-850 \mathrm{~nm}$, respectively (a). The prompt fluorescence induction (not shown) was excited by short laser pulse (50 ls) followed by fast dark-relaxation of complex kinetics demonstrating only slight deceleration upon greening (b)

As the ICM formation is repressed by high oxygen tension, increasing the oxygen partial pressure results in disruption of ICM assembly together with disintegration of the photosynthetic complexes. The kinetics and oxygendependence of these processes were tracked and demonstrated in 3D relief maps (Fig. 6). The depigmentation of the culture upon anaerobic to aerobic transition is more completed and faster at higher oxygen concentrations. As the disintegration of the BChl components in the LH complexes is not uniform, the partition of the $\mathrm{BChl}$ forms show significant variations. This can be seen by plotting the kinetics of the B800/B850 ratio of the LH2 and the B875/ B850 ratio of the LH1/LH2 systems as a function of the oxygen tension (Fig. 6a). The B800 
component of the LH2 complex exhibits fast (several hours) partial (*50\%) drop at relatively small (*5\%) oxygen tension, while no loss of the B850 component is observed. The effect can be due to different location and coupling of the two cyclic BChl systems in LH2 (Papiz et al. 1995). The 9 loosely bound BChls of the B800 band are at the outer ring and the 18 strongly excitonically coupled BChls of the B850 band are inside the complex. That difference can make B800 more vulnerable to oxygen tension. Both the initial rise of the ECS that measures the extent of charge separation in the RC and the maximum level of the fluorescence induction (Fmax, the RCs are closed) characteristic of LH complexes show decays similar to that of B800 under the same conditions (Fig. 6b). These findings indicate that the loss of P800 of the RC can contribute to the observed decrease of the absorption at $800 \mathrm{~nm}$, but the disruption of B800 should play the determining role.
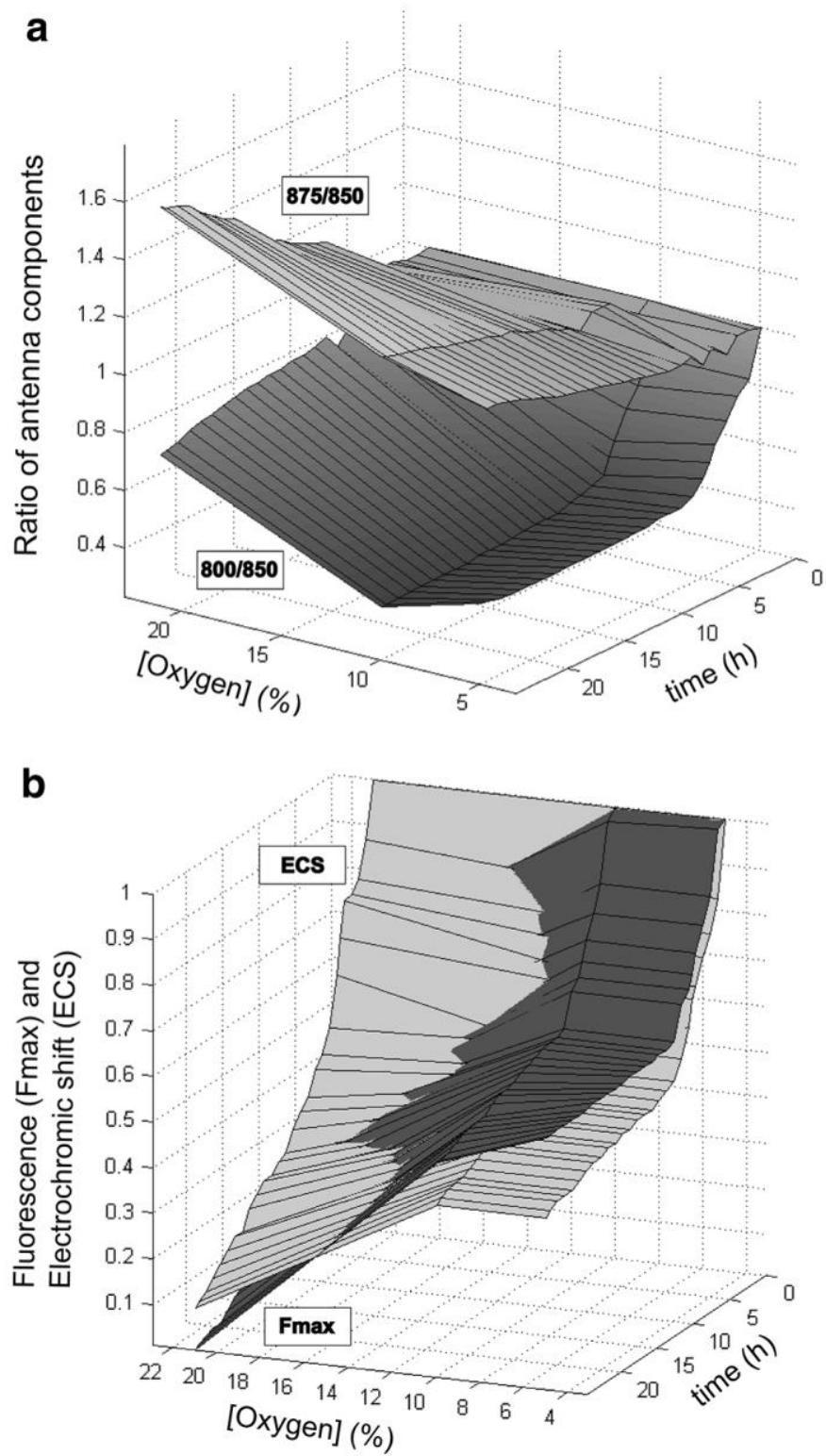

Fig. 6 Changes of relative portion of BChl forms B800, B850 and B875 in antenna complexes (a) and maximum fluorescence of induction (Fmax) and magnitude of flash-induced electrochromic shift (ECS) (b) as a function of time (t) of exposure to (semi)aerobic conditions of different oxygen tensions between 0 and $21 \%$. The kinetics are normalized to 1 at $\mathrm{t}=0 \mathrm{~h}$. The oxygen bleaching targets primarily the B800 pigment of LH2 and the RC complex (significant disintegration occurs at oxygen tension as low as $5 \%$ ). See the colored animation in the Supplement for more detailed demonstration 


\section{Discussion}

These experiments clearly demonstrated the structural and functional changes of the photosynthetic membrane upon division, asynchronous growth and aerobic $\leftrightarrow \rightarrow$ anaerobic transitions of the bacterium Rba. sphaeroides. We will attempt to offer a coherent view of the results obtained by different methods.

\section{Cell-cycle-related phenomena}

The incorporation of photosynthetic pigments and major protein complexes (LHC and RC) was found to occur continuously in synchronously dividing cell populations. The continuous synthesis of total particulate proteins and photopigments during the synchronous growth (Wraight et al. 1978) was in marked contrast to the observed discontinuous accumulation of cellular phospholipid (Lueking et al. 1978) and membrane potential (Fig. 3). Membrane phospholipids are known to be involved with the numerous functional and structural activities. Although the accumulation of phospholipids in the ICM was found discontinuous with respect to the cell cycle, the rates of synthesis of the individual phospholipid species remained constant with respect to one another throughout the cell cycle (Cain et al. 1981). Similarly, each of these phospholipid species appeared to be transferred simultaneously to the ICM. As neither the partition of production nor the transfer of the phospholipids showed cell-cycle dependence, it can be concluded that the total amount of the phospholipids synthesized in the cell is sensitive to the division. Upon division of the cell, the area of the total membrane surface of the cell should increase significantly due to the resulting daughter cells with their own outer, cytoplasmic and ICM membrane systems. This is a highly energy consuming process that should influence the phospholipid synthesis of the whole cell. This is why a burst of phospholipid synthesis occurs prior to cell division and the phospholipids will be inserted into the replicating ICM as it is being partitioned to daughter cells. At the time of cell division, however, the synthesis of the phospholipids is transiently interrupted, and no new phospholipids will be incorporated into the ICM. The protein to phospholipid ratio of the ICM undergoes cyclical fluctuations during synchronous growth of the organism. The change can directly influence the activities of membranous protein complexes and the physical state of the membrane seen by modulation of the polarization of a fluorescence probe upon cell division (Fraley et al. 1979). The uncoupling of protein and lipid incorporation into the ICM immediately preceding or at the time of cell division has widespread consequences as it is believed to reflect the influence of ICM proteins in modulating bulk membrane fluidity and crowding (determined by the protein/phospholipid ratio) (Kiley and Kaplan 1988). The cell-cycle specific changes of the fluidity will influence the supercomplex structure of the photosynthetic apparatus in Rba. sphaeroides, the mobility of the species in the cyclic electron transfer and the properties of the reporter molecules (BChl and carotenoids) by several ways. (1) The signaling species are usually bound to integral membrane proteins immersed in the ICM. For example, the yield of Chl a fluorescence is sensitive to the hydrophobicity of the surroundings: it is high when immersed in the membrane and becomes lower when partitioned in the aqueous phase (Murata and Fork 1975). The process is controlled by the fluidity of the membrane. (2) The average distance between the PSU will decrease and therefore the connectivity will increase upon crowding the membrane via increased protein/phospholipid ratio. (3) If the crowding is mainly due to the increase of the local concentration of the LH2 complex in tightly packed arrangement of the complexes (e.g., Rba. sphaeroides grown at low light intensity), then the long-range pathways for lateral diffusion of quinone redox species between RC and cyt bc1 complexes will increase (Woronowicz et al. 2012). On the other hand, the dense packing of RC-LH1- PufX and LH2 complexes favors efficient light capturing. Because of the conflicting requirements between lateral diffusion of quinone/quinol and yield of energy transfer, it is hard to predict the observed rate of electron turnover. In our experiments, the electrochromic change that is connected to the energetization of the membrane, demonstrates cell-cycle-dependent increase upon cultivation (Fig. 3a). The changes observed during the cell cycle can be attributed either to shorter distance of diffusion (membrane bilayer crowding) or to increased diffusion coefficient (increased fluidity of the membrane) or to both effects. The initial production of photosynthetic membrane components asynchronous with the cell cycle showed marked lag phases with different duration and various rates in the exponential phase indicating different ways of insertion into the newly assembled structure (Fig. 3b-d). It can be suggested that some elements of the PSU (e.g., the RC-B875 core complex or the cyt bc1 complex) are thought to be inserted preferentially into membrane growth initiation sites and the incomplete PSUs are transferred from their sites of assembly into the ICM during cell division. Other elements of the PSU (e.g., the B800-850 peripheral LH complexes) are added directly to the ICM throughout the cell cycle (Wraight et al. 1978; Kiley and Kaplan 1988). 
Some essential functional aspects of the photosynthetic unit assembly process during aerobic ? anaerobic transition can be obtained by analysis of the kinetics of induction and relaxation of the variable fluorescence. The evaluation, however, becomes somewhat more difficult as not all RCs in intact cells of Rba. sphaeroides strain Ga are supposed to organize in ICM. Vermeglio and Joliot (2014) estimated that about $17 \%$ of the total number of RCs is localized in non-invaginated part of the membrane. They share cytochromes c2 and cyt bc1 complexes with the respiratory chains. That could be the reason why a small variable fluorescence remains even after prolonged bleaching of the ICM (Fig. 4c). The quantum yield of the primary photochemistry during the early stages of adaptation showed a gradual increase [variable/maximal fluorescence from 0.1 to 0.7 between 0 and $4 \mathrm{~h}$ (Fig. $4 \mathrm{c}$ )], while the initial value of the photochemical rate constant of $2104 \mathrm{~s}-1$ gradually increased to 7104 s-1 over $6 \mathrm{~h}$ (Fig. $4 d)$. These dramatic increases showed a direct relation to gradual increase of the absorption cross section of the PSU by increase of the size and connectivity of the light gathering units. Simultaneously, the rate of P? re-oxidation by mobile reduced cyt $\mathrm{c}_{2}$ measured by the rate of fluorescence relaxation showed slight and monotonous decrease from $\sim 1.5104 \mathrm{~s}-1$ to $\sim 6103 \mathrm{~s}-1$ that would include a $\sim 2.5$-fold slowing of the shuttle of the electron between the RC and the cyt bc1 complex during greening. In contrast to our results, Koblizek et al. (2005) described a more dramatic change of the electron transfer rate upon transition from aerobic to semiaerobic conditions. They reported at $1 \mathrm{~h}$ of greening extremely slow relaxation that turned to very fast decay at $4 \mathrm{~h}$ and finally became significantly slower at $24 \mathrm{~h}$ in fully developed cells. Niederman (2013) reported close to tenfold slowing of the rate of electron transfer turnover during de novo formation of the ICM at low aeration. The modest and monotonous drop of the rates in our experiments is not due to changes in cyt c2 pool size, but rather to longer cyt c2 periplasmic diffusion pathways between the RC and cytochrome bc1 complex. The developed (mature) membrane becomes more densely packed with $\mathrm{LH} 2$ rings and/or the distal RC in the dimer turns to be less easily accessible to cyt $\mathrm{c} 2$. The conclusion is supported by functional proteomic analysis of the ICM development process performed in Rba. sphaeroides during adaptation from highintensity illumination to indirect diffuse light (Woronowicz et al. 2011). Our results favor previous suggestions arguing that the photosynthetic apparatus during greening is assembled in functional unit not in one step but in a sequential manner (Koblizek et al. 2005; Niederman 2006). The major processes of photosynthetic complex assembly can be summarized in the following model (Fig. 7). Under aerobic conditions, low levels of the RC-LH1-PufX complex are built and inserted into CM in a form that is highly inactive in light capture and forward electron transfer. At the beginning of adaptation to the anaerobic conditions, ICM is formed after invagination and vesicularization of the CM. The peripheral light harvesting antenna (LH2) starts to surround the core complex that improves the yield and rate of photochemical conversion. The initially loose structure of the supercomplex facilitates the access of cyt $\mathrm{c}_{2}$ to the RC and cyt bc1 complexes that makes fast cyclic electron transfer available. Upon synthesis and insertion of more and more LH2 complexes, the membrane becomes more densely packed and the diffusion of mobile redox species will be partially hindered. After $3-4 \mathrm{~h}$, the regular anaerobic photosynthetic competence is achieved with optimal organization of the cyclic electron transport chain. Similar mechanism of sequential assembly has been observed for PS I and PS II in cyanobacteria (Cline 2003). Additionally, the initial synthesis of the thylakoid membranes in plant proplastids may involve invagination of the inner envelope, into which thylakoid proteins were first inserted.

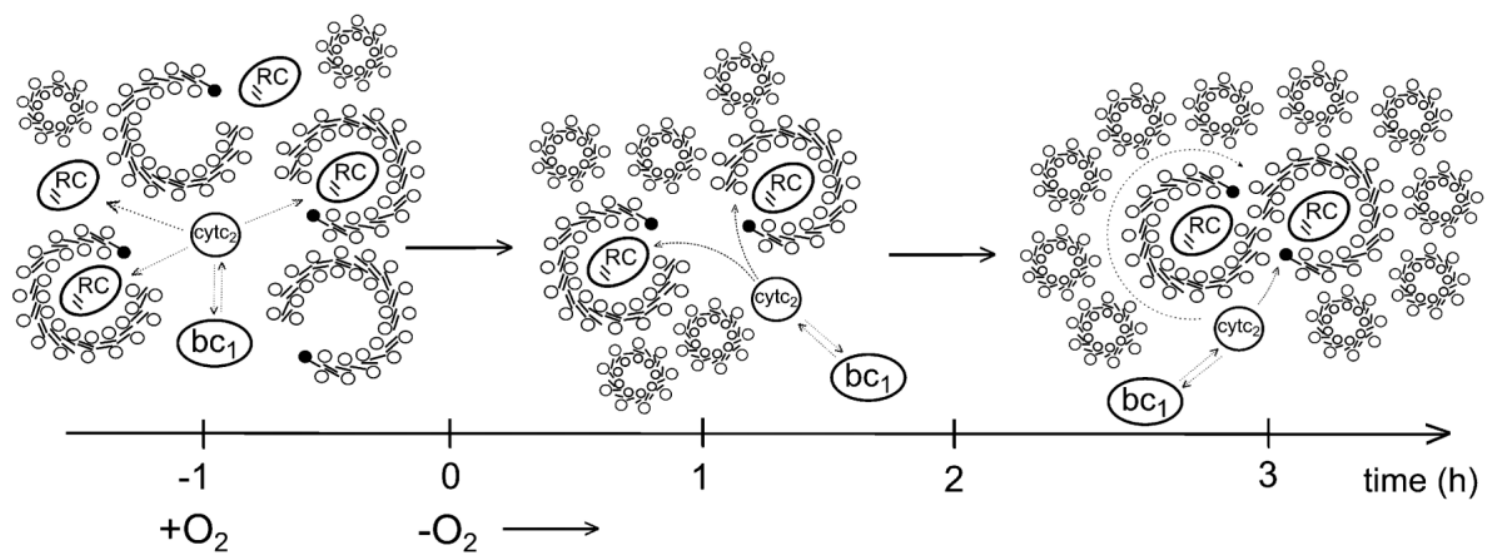

Fig. 7 Simplified sequential model of assembly of the bacterial photosynthetic apparatus upon greening. Initially, the highly unconnected units keep the yield and rate of photochemistry low but make the protein complexes (RC and cyt bc1) readily accessable to the mobile redox species (cyt $\mathrm{c}_{2}$ and $\mathrm{Q}$ ) that assures high electron transfer rate. Later, the connectivity of the

PSU increases and the structure becomes more compact resulting in more efficient and fast photochemistry. Finally, peripheral LH2 in excess is assembled and the closed supercomplex structure is established. The mobile redox shuttles get 
less access to distal RC of the dimer in the crowded membrane which may slightly decrease the rate of electron transfer. For more exact recent details of the structures of the components obtained from AFM, EM and MS see Cartron et al. (2014)

The knowledge gained from synchronization and greening of the bacterial culture contributes to the great wealth of information that has been accumulated about the induction and assembly of the ICM and its connection to the photosynthetic apparatus. Many other issues, however, remained to be resolved including better understanding of formation, development and function of ICM invaginations from CM membrane and how these structural changes determine the activity of the different components of the photosynthetic apparatus. The proteomics and dynamics of the ICM at the level of structural resolution covering wide time scales (from femtoseconds to hours) together with spectroscopic and functional studies constitute perspectives for the next years.

\section{Outlook}

Advances in spectroscopic and kinetic techniques in combination with structural information during the past few years have vastly improved our knowledge on the mechanism of photosynthetic energy transduction and biological electron transfer. Further extensive characterization of the problems of membrane development of photosynthetic bacteria will certainly constitute the bases for new breakthroughs in organization and function of the complexes. These findings will set the stage for engineering new biological functions, new materials and new facilities based on light-induced redox chemistry mimicking the natural system (Maro 'ti and Trotta 2012; Jackson et al. 2014).

\section{Acknowledgments}

Authors thank to TÁMOP 4.2.2.A-11/1 KONV- 2012-0060, TA ' MOP 4.2.2.B and COST Actions on "Molecular machineries for ion translocation across biomembranes" (CM0902) and "Understanding Movement and Mechanism in Molecular Machines" (CM1306) programs for financial support.

\section{References}

Aagaard J, Sistrom WR (1972) Control of synthesis of reaction center bacteriochlorophyll in photosynthetic bacteria. Photochem Photobiol 15:209-225

Asztalos E, Maróti P (2009) Export or recombination of charges in reaction centers in intact cells of photosynthetic bacteria. Biochim Biophys Acta 1787:1444-1450

Asztalos E, Kis M, Maróti P (2010a) Aging photosynthetic bacteria monitored by absorption and fluorescence changes. Acta Biol Szeged 54(2):149-154

Asztalos E, Italiano F, Milano F, Maro 'ti P, Trotta M (2010b) Early detection of mercury contamination by fluorescence induction of photosynthetic bacteria. Photochem Photobiol Sci 9:1218-1223

Bahatyrova S, Frese RN, Siebert CA, Olsen JD, van der Werf KO, van Grondelle R, Niederman RA, Bullough PA, Otto C, Hunter CN (2004) The native architecture of a photosynthetic membrane. Nature 430:1058-1062

Bartlett GR (1959) Phosphorus assay in column chromatography. J Biol Chem 234:466-468

Bauer CE, Setterdahl A, Wu J, Robinson BR (2009) Regulation of gene expression in response to oxygen tension. In: Hunter CN, Daldal F, Thurnauer M, Beatty JT (eds) Advances in photosynthesis and respiration: the purple phototrophic bacteria. Springer, Dordrecht, pp 707-725

Bina D, Litvin R, Va 'cha F (2010) Absorbance changes accompanying the fast fluorescence induction in the purple bacterium Rhodobacter sphaeroides. Photosynth Res 105:115-121

Bligh EG, Dyer WJ (1959) A rapid method of total lipid extraction and purification. Can J Biochem Physiol 37:911-917

Cain BD, Deal CD, Fraley RT, Kaplan S (1981) In vivo intermembrane transfer of phospholipids in the photosynthetic bacterium Rhodopseudomonas sphaeroides. J Bacteriol 145(3):1154-1166

Callister SJ, Nicora CD, Zeng X, Roh JH, Dominguez MA, Tavano CL, Monroe ME, Kaplan S, Donohue JT, Smith RD, Lipton MS (2006) Comparison of aerobic and photosynthetic Rhodobacter sphaeroides 2.4.1 proteomes. J Microbiol Methods 67(3):424-436 
Cartron ML, Olsen JD, Sener M, Jackson PJ, Brindley AA, Qian P, Dickman MJ, Leggett GJ, Schulten K, Hunter CN (2014) Integration of energy and electron transfer processes in the photosynthetic membrane of Rhodobacter sphaeroides. Biochim Biophys Acta. doi:10.1016/j.bbabio.2014.02.003

Clayton RK (1966) Spectroscopic analysis of bacteriochlorophylls in vitro and in vivo. Photochem Photobiol 5:669-688

Clayton RK, Clayton BJ (1981) B850 pigment-protein complex of Rhodopseudomonas sphaeroides: extinction coefficients, circular dichroism, and the reversible binding of bacteriochlorophyll. Proc Natl Acad Sci USA 78(9):5583-5587

Cline K (2003) Biogenesis of green plant thylakoid membranes. In: Green BR, Parson WW (eds) Light-harvesting antennas in photosynthesis (advances in photosynthesis and respiration), vol 13. Kluwer Academic Publishers, Dordrecht, pp 353-372

Comayras F, Jungas C, Lavergne J (2005) Functional consequences of the organization of the photosynthetic apparatus in Rhodobacter sphaeroides: I. Quinone domains and excitation energy transfer in chromatophores and reaction center antenna complexes. J Biol Chem 280:11203-11213

Crofts AR, Guergova-Kuras M, Hong S (1998) Chromatophore heterogeneity explains phenomena seen in Rhodobacter sphaeroides previously attributed to supercomplexes. Photosynth Res 55:357-362 Cutler RG, Evans JE (1966) Synchronization of bacteria by a stationary-phase method. J Bacteriol 91(2):469-476

Fedotova J, Zeilstra-Ryalls J (2014) Analysis of the role of PrrA, PpsR, and FnrL in intracytoplasmic membrane differentiation of Rhodobacter sphaeroides 2.4.1 using transmission electron microscopy. Photosynth Res 119:283-290

Feniouk BA, Junge W (2009) Proton translocation and ATP synthesis by the F0F1-ATPase of Purple bacteria. In: Hunter CN, Daldal F, Thurnauer M, Beatty JT (eds) Advances in photosynthesis and respiration: the purple phototrophic bacteria. Springer, Dordrecht, pp 475-493

Fraley RT, Yen GSL, Lueking DL, Kaplan S (1979) The physical state of the intracytoplasmic membrane of Rhodopseudomonas sphaeroides and its relationship to the cell division cycle. J Biol Chem 254(6):1987-1991

Gomelsky M, Zeilstra-Ryalls JH (2013) The living genome of a purple nonsulfur photosynthetic bacterium: overview of the Rhodobacter sphaeroides transcriptome landscapes. In: Beatty JT (ed) Genome evolution of photosynthetic bacteria, vol 66, 1st edn. Academic Press, San Diego

Joliot P, Vermeglio A, Joliot A (1989) Evidence for supercomplex between reaction centers, cytochrome c2 and cytochrome bc1 complex in Rhodobacter sphaeroides whole cells. Biochim Biophys Acta 975:336-345

Kiley PJ, Kaplan S (1988) Molecular genetics of photosynthetic membrane biosynthesis in Rhodobacter sphaeroides. Microbiol Rev 52(1):50-69

Knacker T, Harwood JL, Hunter CN, Russell NJ (1985) Lipid biosynthesis in synchronized cultures of the photosynthetic bacterium Rhodopseudomonas sphaeroides. Biochem J 229: 701-710

Koblizek M, Shih JD, Breitbart SI, Ratcliffe EC, Kolber ZS, Hunter CN, Niederman RA (2005) Sequential assembly of photosynthetic units in Rhodobacter sphaeroides as revealed by fast repetition rate analysis of variable bacteriochlorophyll a fluorescence. Biochim Biophys Acta 1706:220-231

Kocsis P, Asztalos E, Gingl Z, Maro 'ti P (2010) Kinetic bacteriochlorophyll fluorometer. Photosynth Res 105:73-82

Lavergne J, Vermeglio A, Joliot P (2009) Coupling between RC and cytochrome bc1 complex. In: Hunter CN, Daldal F, Thurnauer M, Beatty JT (eds) Advances in photosynthesis and respiration: the purple phototrophic bacteria. Springer, Dordrecht, pp 509-536

Lueking DR, Fraley RT, Kaplan S (1978) Intracytoplasmic membrane synthesis in synchronous cell populations of Rhodopseudomonas sphaeroides. J Biol Chem 253(451-457):17

Lueking DR, Campbell TB, Burghardt RC (1981) Light- induced division and genomic synchrony in phototrophically growning cultures of Rhodopseudomonas sphaeroides. J Bacteriol 146(2): 790-797

Maróti P, Asztalos E (2012) Calculation of connectivity of photosynthetic units in intact cells of Rhodobacter sphaeroides. In: $\mathrm{Lu} \mathrm{C}$ (ed) Research for food, fuel and future-15th international conference on photosynthesis, pp 27-31

Maróti P, Trotta M (2012) Artificial photosynthetic systems. In: Griesbeck A, Oelgemo "1ler M, Ghetti F (eds) CRC handbook of organic photochemistry and photobiology. CRC Press, Boca Raton, pp 1289-1324

Maróti P, Wraight CA (1988) Flash-induced H? binding by bacterial photosynthetic reaction centers: comparison of spectrometric and conductometric methods. Biochim Biophys Acta 934:314-328 
Maróti P, Asztalos E, Sipka G (2013) Fluorescence assay for photosynthetic capacity of bacteria. Biophys J 104(2):545a

Marquardt DW (1963) An algorithm for least-squares of estimation of nonlinear parameter. J Soc Ind Appl Math 11:431-441

Masuda S, Bauer CE (2002) AppA is a blue light photoreceptor that antipresses photosynthesis gene expression in Rhodobacter sphaeroides. Cell 110:613-623

Megiatto JD, Me 'ndez-Herna 'ndez DD, Tejeda-Ferrari ME, Teillout AL, Llansola-Portole 's MJ, Kodis G, Poluektov OG, Rajh T, Mujica V, Groy TL, Gust D, Moore TA, Moore AL (2014) A bioinspired redox relay that mimics radical interactions of the Tyr-His pairs of photosystem II. Nat Chem. doi:10.1038/nchem. 1862

Mozharov AD, Shchipakin VN, Fishov IL, Evtodienko YV (1985) Changes in the composition of membrane phospholipids during the cell-cycle of Escherichia coli. FEBS Lett 186:103-106

Murata N, Fork DC (1975) Temperature dependence of chlorophyll a fluorescence in relation to the physical phase of membrane lipids in algae and higher plants. Plant Physiol 56:791-796

Niederman RA (2006) Structure, function and formation of bacterial intracytoplasmic membranes. In: Shively JM (ed) Complex intracellular structures in prokaryotes, microbiology monographs, vol 2. Springer, Berlin, pp 193-227

Niederman R (2013) Membrane development in purple photosynthetic bacteria in response to alterations in light intensity and oxygen tension. Photosynth Res 116:333-348 Oh JI, Kaplan S (2000) Redox signaling: globalization of gene expression. EMBO J 19:4237-4247

Papiz MZ, Cogdell RJ, Isaacs NW (1995) Crystal structure of an integral membrane light-harvesting complex from photosynthetic bacteria. Nature 374:517-521

Qian P, Bullough PA, Hunter CN (2008) Three-dimensional reconstruction of a membrane-bending complex: the RC-LH1PufX core dimer of Rhodobacter sphaeroides. J Biol Chem 283:14002-14011

Rivoyre M, Ginet N, Bouyer P, Lavergne J (2010) Excitation transfer connectivity in different purple bacteria: a theoretical and experimental study. Biochim Biophys Acta 1797:1780-1794

Scheuring S (2009) The supramolecular assembly of the photosynthetic apparatus of purple bacteria investigated by highresolution atomic force microscopy. In: Hunter CN, Daldal F, Thurnauer M, Beatty JT (eds) Advances in photosynthesis and respiration: the purple phototrophic bacteria. Springer, Dordrecht, pp 941-952

Sener MK, Schulten K (2009) From atomic-level structure to supramolecular organization in the photosynthetic unit of purple bacteria. In: Hunter CN, Daldal F, Thurnauer M, Beatty JT (eds) Advances in photosynthesis and respiration: the purple phototrophic bacteria. Springer, Dordrecht, pp 275-294

Sener MK, Olsen JD, Hunter CN, Schulten K (2007) Atomic-level structural and functional model of a bacterial photosynthetic membrane vesicle. Proc Natl Acad Sci USA 104:15723-15728

Sistro "m WR (1962) The kinetics of the synthesis of photopigments in Rhodopseudomonas sphaeroides. J Gen Microbiol 28:607-616 Stirbet A, Govindjee (2012) Chlorophyll a fluorescence induction: a personal perspective of the thermal phase, the J-I-P rise. Photosynth Res 113:15-61

Sturgis JN, Niederman RA (2009) Organization and assembly of light-harvesting complexes in the purple bacterial membrane. In: Hunter CN, Daldal F, Thurnauer M, Beatty JT (eds) Advances in photosynthesis and respiration: the purple phototrophic bacteria. Springer, Dordrecht, pp 253-273

Takemoto J, Lascelles J (1973) Coupling between bacteriochlorophyll and membrane protein synthesis in Rhodopseudomonas sphaeroides. Proc Natl Acad Sci USA 70:799-803

Tucker JD, Siebert CA, Escalante M, Adams PG, Olsen JD, Otto C, Stokes DJ, Hunter CN (2010) Membrane invagination in Rhodobacter sphaeroides is initiated at curved regions of the cytoplasmic membrane, then forms both budded and fully detached spherical vesicles. Mol Microbiol 76:833-847

Vermeglio A, Joliot P (2014) Modulation of the redox state of quinines by light in Rhodobacter sphaeroides under anaerobic conditions. Photosynth Res 120:237-246

Woronowicz K, Sha D, Frese RN, Niederman RA (2011) The accumulation of the light-harvesting 2 complex during remodeling of the Rhodobacter sphaeroides intracytoplasmic membrane results in a slowing of the electron transfer turnover rate of photochemical reaction centers. Biochemistry 50(22):4819-4829 
Woronowicz K, Olubanjo OB, Sung HC, Lamptey JL, Niederman RA (2012) The effects of protein crowding in bacterial photosynthetic membranes on the flow of quinone redox species between the photochemical reaction center and the ubiquinol-cytochrome c2 oxidoreductase. Photosynth Res 111(1-2):125-138

Woronowicz K, Harrold JW, Kay JM, Niederman RA (2013) Structural and functional proteomics of intracytoplasmic membrane assembly in Rhodobacter sphaeroides. J Mol Microbiol Biotechnol 23:48-62

Wraight CA (2006) Chance and design—proton transfer in water, channels and bioenergetic proteins. Biochim Biophys Acta 1757:886-912

Wraight CA, Lueking DR, Fraley RT, Kaplan S (1978) Synthesis of photopigments and electron transfer components in synchronous Phototropic cultures of Rhodopseudomonas sphaeroides. J Biol Chem 253(2):465-471

Young CS, Beatty JT (2003) Multi-level regulation of purple bacterial light-harvesting complexes. In: Green BR, Parson WW (eds) Light harvesting antennas in photosynthesis. Kluwer Academic Publishers, Dordrecht, pp 449-470

Zeng F, Roh JH, Callister SJ, Tavano CL, Donohue TJ, Lipton MS, Kaplan S (2007) Proteomic characterization of the Rhodobacter sphaeroides 2.4.1 photosynthetic membrane: identification of new proteins. J Bacteriol 189(20):7464-7474

Zwietering MH, Rombouts FM, van't Riet K (1992) Comparison of definitions of the lag phase and the exponential phase in bacterial growth. J Appl Bacteriol 72(139-145):20 